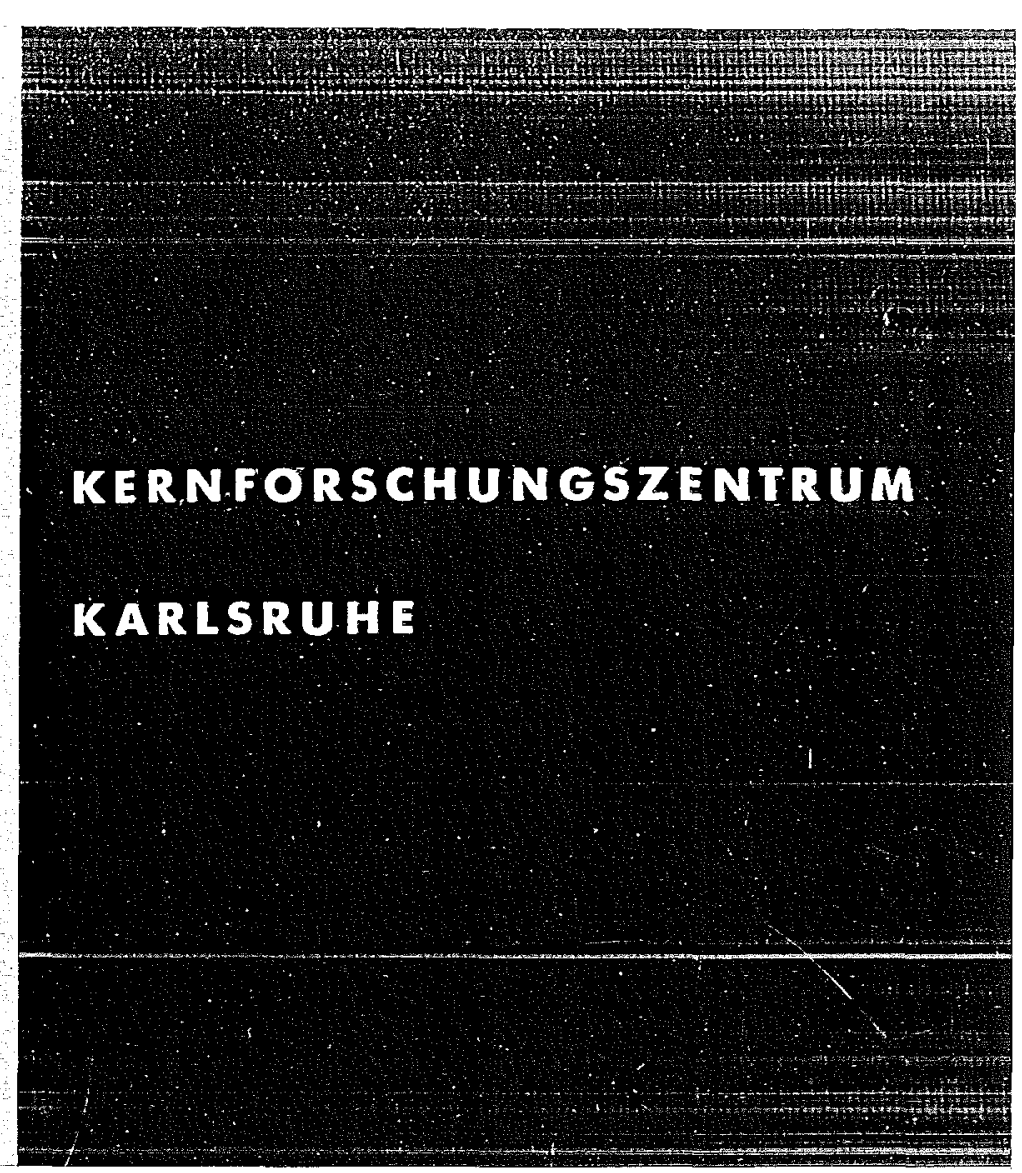

Institut füı. Strahlenbiologie

EPR of Fast Repair Reacitions by Sulfhydryl and Disuifide

Compounds ir: Aqueous Solutions

C. Nicolizu, $H_{0}$ Derting er

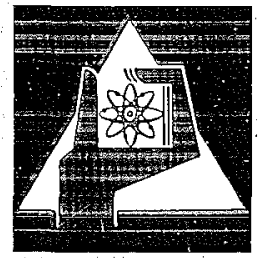

GESELLSCHAFT FUR KERNFORSCHUNG M.B.H KARLSRUHE 


\title{
EPR of Fast Repair Reactions by Sulfhydryl and Disulfide Compounds in Aqueous Solutions
}

\author{
CLAUDE NICOLAU ${ }^{1}$ AND HERMANN DERTINGER
}

Institut für Strahlenbiologie, Kernforschungszentrum Karlsmhe, Germany

\begin{abstract}
Nicolau, Claude, and Dertinger, Hermann. EPR of Fast Repair Reactions by Sulfhydryl and Disulfide Compounds in Aqueous Solutions. Radiation Res. 42, 62-72 (1970).

Electron paramagnetic resonance (EPR) investigations were performed with a two-way and a three-way flow technique in order to follow the reaction of sulfhydryls and disulfides with various organic free radicals. The organic compounds were attacked with $\mathrm{OH}$ or $\mathrm{NH}_{2}$ radicals produced in a $\mathrm{Ti}^{3+}+\mathrm{H}_{2} \mathrm{O}_{2}\left(\mathrm{NH}_{2} \mathrm{OH}\right)$ system and subsequently reacted with $\mathrm{RSH}$ or RSSR compounds. Direct evidence of hydrogen transfer from RSH to both abstraction and addition radicals has been obtained. For disulfides a cation-radical mechanism has been advanced in order to explain the disappearance of free radicals when the latter react with such compounds.
\end{abstract}

\section{INTRODUCTION}

Much interest has been focussed during the last years on two types of radioprotective substances: $\mathrm{SH}$-containing compounds such as thiols, mercaptanes, and organic disulfides. Considerable experimental evidence has accumulated, showing that these compounds exert a definite radioprotective effect on biomolecules, microorganisms, cells, and whole organisms $(1-4)$. The sulfur compounds most frequently used in such experiments were cysteine, cysteamine, cystamine, thioglycol, reduced glutathione, etc. Two mechanisms have been advanced in order to account for the protective ability of SH-compounds in solutions as well as in the dry state:

1. They act as radical scavengers for radiation induced free radicals as $\mathrm{H}^{\bullet}, \mathrm{OH}^{*}$ and the hydrated electron $\mathrm{e}_{\mathrm{aq}}^{-}$, thus protecting biological structures against the indirect effect of radiation (5).

2. The SH-compounds interact directly with the damaged biomolecules and effect their repair $(6,7)$.

${ }^{1}$ Permanent address: Institute of Inframicrobiology "Stefan Nicolau", Bucharest, Rumania. 
Both mechanisms take into account the observation that RS radicals are detected in EPR experiments with biomolecules irradiated in the presence of SHcompounds $(8,9)$. There is evidence also that these compounds exert additional protection on T1 phages as compared with "ordinary" radical scavengers as histidine or even nutrient broth (10). Pulse radiolysis experiments $(11,12)$ demonstrated a repair process in which hydrogen is transferred from cysteamine to the damaged molecules.

In the present paper we report experiments performed by means of EPR spectroscopy in conjunction with a flow technique as described by Dixon and Norman (19) and by Norman and West (14). This technique allows detection of short lived free radicals produced by the attack with $\mathrm{OH}^{-}$and $\mathrm{NH}_{2}{ }^{\circ}$ and to follow their reaction with organic molecules. The $\mathrm{OH}$ and $\mathrm{NH}_{2}$ radicals are produced by the following reactions:

$$
\begin{aligned}
\mathrm{Ti}^{3+}+\mathrm{H}_{2} \mathrm{O}_{2} & \rightarrow \mathrm{Ti}^{4+}+\mathrm{OH}^{-}+\mathrm{OH}^{\cdot} \\
\mathrm{Ti}^{3+}+\mathrm{NH}_{2} \mathrm{OH} & \rightarrow \mathrm{Ti}^{4+}+\mathrm{OH}^{-}+\mathrm{NH}_{2}
\end{aligned}
$$<smiles>C1C[Te][Te]C1</smiles>

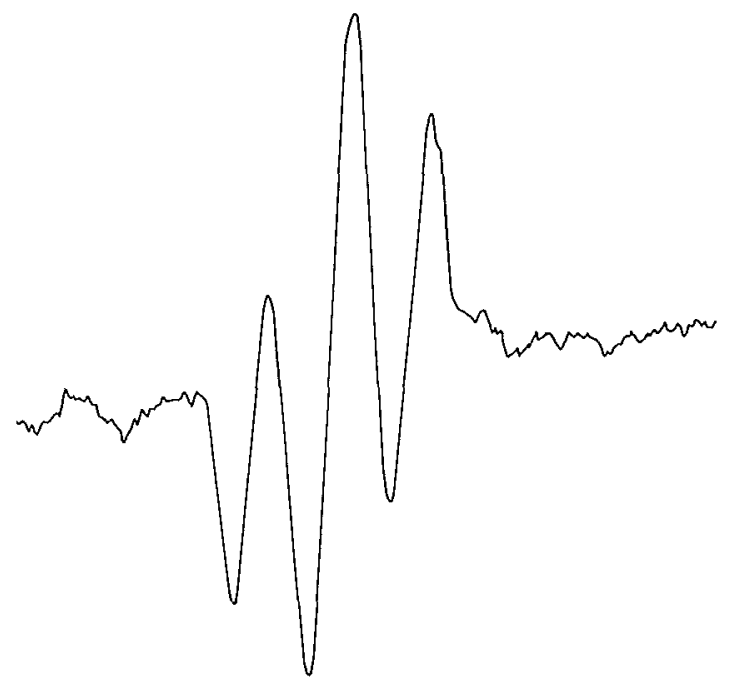

$$
10 \mathrm{G}
$$

FIG. 1. EPR signal of the radical RS produced by the reaction of dissolved cysteine, cystine, cysteamine and cystamine with $\mathrm{OH}{ }^{\cdot}$ as well as by the reaction of $\mathrm{NH}_{2}{ }^{\cdot}$ with cysteine and cysteamine. 
Since $\mathrm{OH}^{*}$ is one of the main products of water radiolysis, the "radiomimetic" properties of the titanium-hydrogen peroxide system are obvious. Moreover, it permits investigation of the occurring reactions under controlled kinetic conditions.

\section{MATERIALS AND METHODS}

Ethanol, glucose, thymine, and caffeine (Merck and Fluka products) were used as organic "target molecules" for attack with $\mathrm{OH}^{\prime}$ and $\mathrm{NH}_{2}{ }^{\circ} \cdot \mathrm{TiCl}_{3}$ (solution $12.5 \%$ ), $\mathrm{H}_{2} \mathrm{O}_{2}(30 \%), \mathrm{NH}_{2} \mathrm{OH}$, and the hydrochlorides of cysteine, cysteamine, cystine, and cystamine were purchased from Merck and Schuchardt, respectively. All reagents were used without further purification. An AEG X-Band EPR spectrometer with $125 \mathrm{KHz}$ field modulation was used in conjunction with a Varian aqueous sample flat cell. Mixing of the solution was performed with two types of mixing chambers: a two-way chamber in which two liquids could be flowed and a three-way system in which a third reactant could be introduced into the solution following the admixture of the first two solutions but before passage through the cavity. For a flow rate of about $300 \mathrm{ml} / \mathrm{min}$, the time interval between the first and the second mixing point

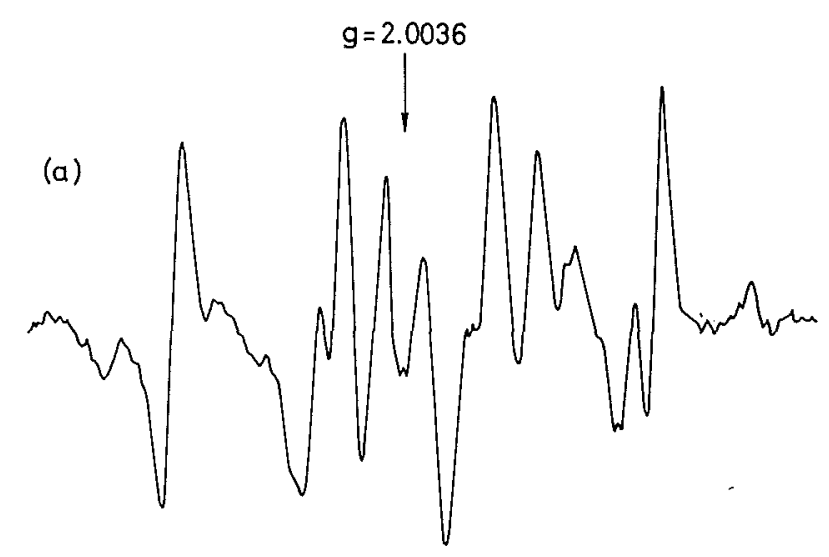

(b)
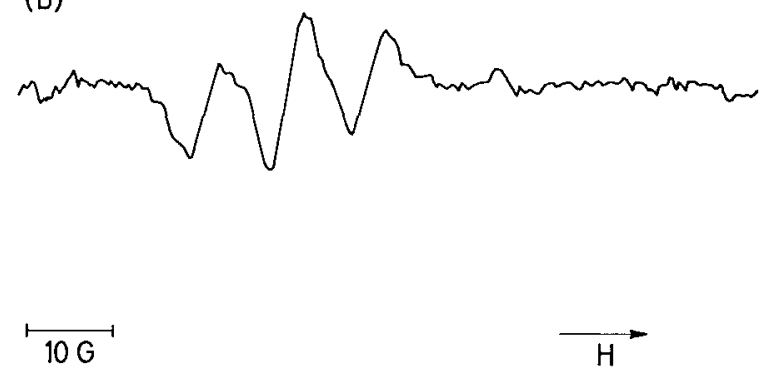

FIG. 2. (a) Glucose radical produced by OH· attack; (b) Cysteine (cysteamine) flowed as a third reactant. 
was about $20 \mathrm{msec}$. The two solutions necessary for the production of the $\mathrm{OH}$ or the

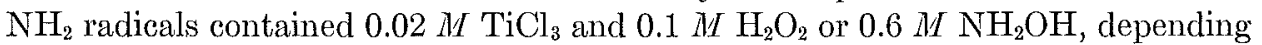
on the desired radical. The organic target molecules were also dissolved in these two solutions. The third solution contained the sulfur compound under investigation in a concentration of $0.05 \mathrm{M}$. All three solutions were acidified with $\mathrm{H}_{2} \mathrm{SO}_{4}$ to a $\mathrm{pH}$ of about 2. The $g$-factors of the EPR spectra were measured with proton resonance against the DPPH value of 2.0036 .

\section{RESULTS}

\section{SH-Compounds}

The spectrum obtained by direct reaction of cysteine and cysteamine with $\mathrm{OH}$ and $\mathrm{NH}_{2}$ radicals, respectively, as measured in a two-way flow experiment, consists

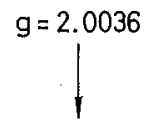

(a)

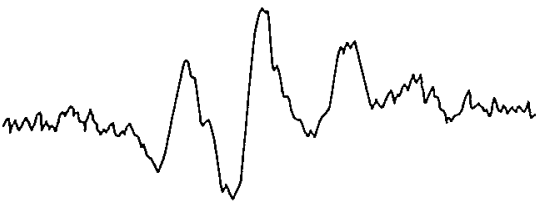

(b)

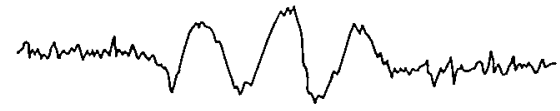

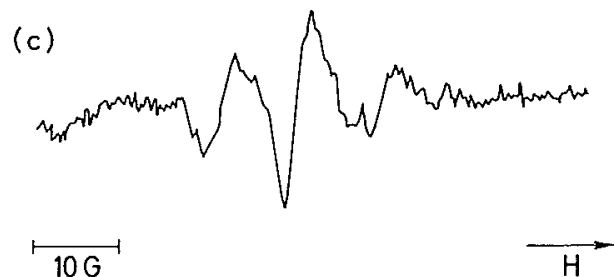

FIG. 3. The dependence of the RS. signal amplitude upon the concentration of thymine as target molecule. Flow rate: $300 \mathrm{ml} / \mathrm{min}$. Same spectrometer settings in (a), (b), and (c). (a) No thymine; (b) $10^{-3} \mathrm{M}$ thymine; (c) $10^{-2} \mathrm{~N}$ thymine. 
of a triplet with a line intensity ratio of $1: 2: 1$ and a hyperfine splitting of $9 \mathrm{G}$ centered at $g=2.0105$ (Fig. 1). If the solution containing the SH-compound was introduced after the reaction of the $\mathrm{OH}$ radicals with the organic target molecules in a three-way flow experiment as described in the experimental section, two characteristic observations were made:

1. The EPR spectrum of the organic radicals produced by $\mathrm{OH}^{*}$ attack disappeared completely (Fig. 2).

2. The triplet pattern of the "sulfur radicals" (Fig. 1) becomes observable.

Clearly, part of the sulfur radicals in this case can be produced by nonreacted $\mathrm{OH}$ radicals. This could be shown in three-way flow experiments in the absence of the organic target molecules. Figure 3a indicates that there is a considerable yield of sulfur radicals even at zero concentration of the organic compound. At low concentration of the organic compound the amplitude of the triplet signal decreases (Fig. 3b), whereas at higher concentration again an increase is observed.

For further elueidation and clarification of this statement, the experiments were repeated using $\mathrm{NH}_{2}{ }^{\circ}$ for the production of the organic radicals instead of $\mathrm{OH}^{*}$. In

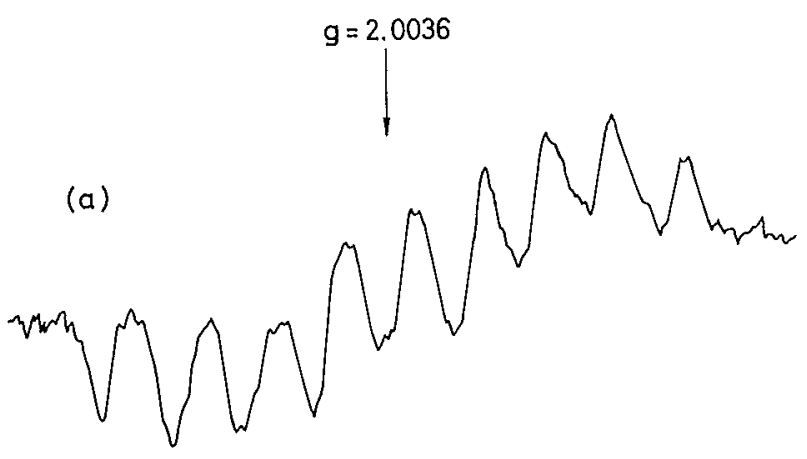

(b)

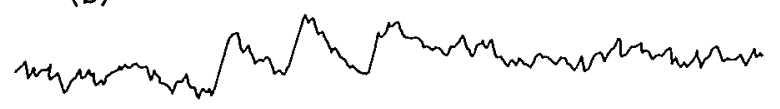

$$
\vdash 10 \mathrm{G}
$$

FIG. 4. (a) EPR spectrum of caffeine after reaction with $\mathrm{NH}_{2}$. (b) Cysteine (cysteamine) flowed as a third reactant. 
this case, however, no sulfur spectrum was detected in the absence of the organic molecules in three-way flow experiments even at high gain setting of the EPR spectrometer. This indicates that the reactivity of the SH-compounds with $\mathrm{NH}_{2}{ }^{\circ}$ is considerably lower than with $\mathrm{OH}^{*}$. In the presence of organic molecules, however, the sulfur signal appears as shown with caffeine in Fig. 4. Among the other organic compounds investigated only thymine reacts like caffeine with the $\mathrm{NH}_{2}$ radical, giving rise to the same results as obtained with caffeine. It is essential to notice that the results 1 and 2 are not observed if the role of the organic and the SHcompounds is interchanged. This means that sulfur radicals once produced are not altered if the solution of the organic molecules is added after the reaction of the SH-compound with $\mathrm{OH}^{*}$ or $\mathrm{NH}_{2}{ }^{*}$ (Fig. 5).

\section{SS-compounds}

The set of experiments just described was also performed with the disulfides cystamine and cystine. The direct reaction of these two compounds with $\mathrm{OH}^{*}$ leads to the production of the same sulfur radical as in the case of the SH-compounds, the spectrum of which is already shown in Fig. 1. However, the attack of

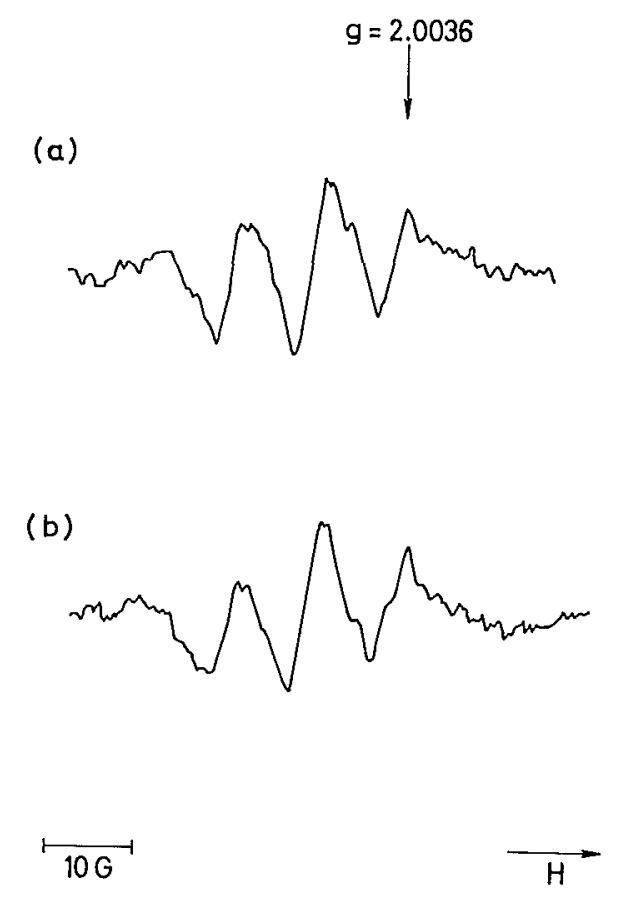

FIG. 5. (a) RS radical produced by the reaction of eysteine or cysteamine with $\mathrm{OH}$ '; (b) Signal obtained if a glucose solution is flowed as third reactant. 


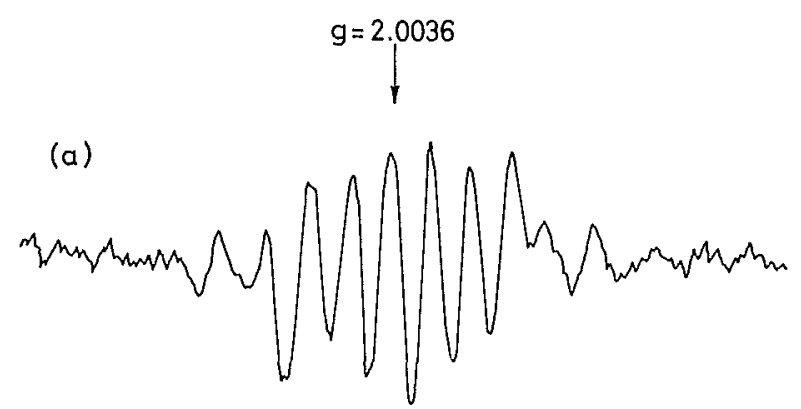

(b)

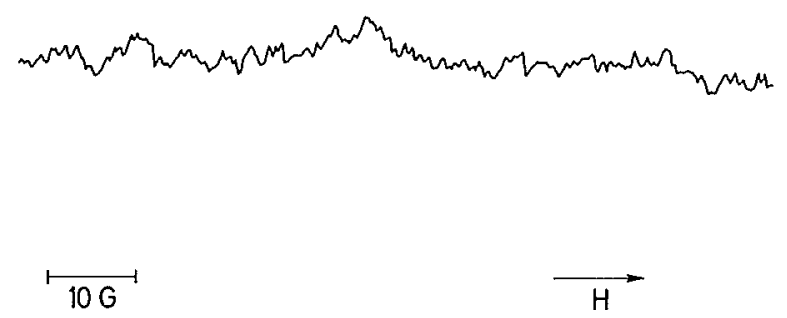

FIG. 6. (a) Radical produced by the reaction of thymine with $\mathrm{NH}_{2}{ }^{\prime}$; (b) Cystine (cystamine) flowed as third reactant.

$\mathrm{NH}_{2}{ }^{\cdot}$ as well as the reaction of the organic radicals with disulfides did not yield the triplet signal in an amount large enough to be detected. Admixture of the disulfide solution through the third way of the mixing chamber only caused the disappearance of the radical spectrum (Fig. 6). In some cases, especially in the experiments with $\mathrm{OH}^{\circ}$, hints of a signal seemed to appear; however, they were neither entirely reproducible nor identifiable. This indicates that another reaction mechanism is working in this case.

\section{DISCUSSION}

Two distinct mechanisms of repair seem to emerge out of these results.

\section{SH-Compounds}

In all cases in which cysteine or cysteamine were used as protective substances, the well-resolved triplet spectrum of Fig. 1 appeared. Due to the high $g$-factor of 2.0105 , the spectrum has been assigned (15) to a radical of the type

$$
\dot{\mathrm{S}}-\mathrm{CH}_{2}-
$$


The triplet signal may be compared with the spectra obtained by irradiation of dry SH-compounds or exposure of these compounds to atomic hydrogen generated in a gaseous discharge. The spectra usually observed in polycrystalline material are strongly asymmetric, showing a characteristic "low field wing" $(16,17)$ which is the consequence of the pronounced $g$-factor anisotropy of the RS radicals. In solution the anisotropic component of the EPR spectrum is averaged, so that in general a symmetric pattern is observed occurring at the average value of the $g$-factor. Although the $g$-factor of the RS triplet is by far higher than the values ever reported for carbon and nitrogen centered free radicals (18), it does not reach the magnitude of the solid state values. This does, however, not affect the correctness of the attribution to a sulfur centered radical. EPR studies on irradiated single crystals of SH- and SS-compounds $(19,20)$ show that the splitting of the two $\mathrm{CH}_{2}$-protons as well as the $g$-factor strongly depend on. the structure of the RS radical. $\mathrm{It}$ is evident that in solution where lattice forces are not acting, a direct comparison of the $g$-factor with the solid state value cannot be made. Another spectrum observed in $\gamma$-irradiated samples of cysteamine free base in vacuo is a $1: 2: 1$-triplet with about $25 G$ splitting and a $g$-factor of $2.0055(17)$ which probably must be attributed to the free radical $\mathrm{NH}_{2}{ }^{\circ}$.

In aqueous solutions the formation of the RS radical is due to the reaction:

$$
\mathrm{RSH}+\mathrm{OH}^{*} \rightarrow \mathrm{RS}^{\bullet}+\mathrm{H}_{2} \mathrm{O}
$$

A similar equation holds for the reaction with $\mathrm{NH}_{2}{ }^{\circ}$. The results of the three-way flow experiments with cysteine or cysteamine as the third reactant, being the disappearance of the spectrum of the organic radical and the appearance of the sulfur triplet, may be formulated in the following equation:

$$
\mathrm{RSH}+\mathrm{X}^{\bullet} \rightarrow \mathrm{RS}^{\bullet}+\mathrm{XH}
$$

In this case $\mathrm{X}^{\cdot}$ is the organic radical produced by $\mathrm{OH}^{\cdot}$ or $\mathrm{NH}_{2}{ }^{*}$ attack. This means that the repair process effected by SH-compounds consists in the donation of a hydrogen atom to the organic radical. Some comment has to be made concerning Fig. 3. In this case a decrease in the amplitude of the RS* signal is observed at low concentration of the target molecules. This is in good agreement with the findings by Chiang et al. (21) who investigated the influence of concentration in $\mathrm{OH}^{*}$ flow experiments with alcohols. They observed that at low alcohol concentration no alcohol signal appeared: instead, an increase of the two characteristic Ti-singlets was registered, indicating that possibly $\mathrm{OH}$ radicals are consumed by reaction with a titanium-alcohol complex. At higher concentrations the Ti-singlets disappeared and the alcohol spectrum was observed. This fact is reflected in the behavior of the sulfur signal amplitude in Fig. 3. Addition of further quantities of the organic compounds leads to a continuous increase of the yield of RS radicals expressing the

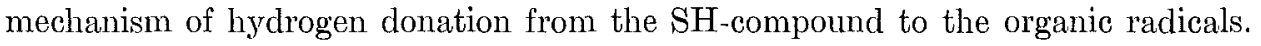


Beyond a certain concentration of the organic target molecules, even in very concentrated solutions, the level of the sulfur signal remained constant, in good agreement with the results of pulse radiolysis experiments by Adams and Michael (22) concerning repair mechanisms by sulfhydryl compounds.

The two typical reactions of $\mathrm{OH}$ radicals with organic molecules are abstraction of atomic hydrogen, as in the case of ethanol (19), and addition to a double bond, as shown for thymine by Nicolau et al. (23). In contrast to this the radical $\mathrm{NH}_{2}{ }^{\circ}$ reacts mainly by addition to a double bond (23) with the exception of SH-compounds. Our results indicate that hydrogen donation is independent of the radical to be repaired even if the radical is nitrogen centered, as in the case of caffeine, where the unpaired spin is located at the position $\mathrm{N}_{7}$ of the imidazole ring ${ }^{2}$. This is shown in Fig. 4. Finally, from the energetic point of view, the hydrogen donation seems to be favored by the relatively low energy of the SH bond $(\sim 87-89 \mathrm{kcal} /$ mole) as compared to the $\mathrm{NH}$ or $\mathrm{CH}$ bond (2).

\section{SS-Compounds}

As already pointed out in the "result"-section $\mathrm{OH}$ radicals react with cystine and cystamine to produce the radical $\mathrm{RS}^{\bullet}$ (Fig. 1). However, no reaction with $\mathrm{NH}_{2}{ }^{\bullet}$ leading to a defined and detectable EPR-signal was observed. In contrast to the situation with SH compounds, three-way flow experiments with disulfides did not lead to the detection of a RS' signal. Only traces of such a signal could be observed in three-way experiments with $\mathrm{OH}^{*}$, resulting probably from its direct reaction with the disulfide. However, the introduction of the SS-containing solution always led to a complete disappearance of the spectrum of the organic radical as observed with the SH compounds (Fig. 6). This indicates that a repair mechanism different from that of the sulfhydryls has to be assumed. Remembering that the experiments were performed at acid $\mathrm{pH}$, we suggest the following reaction sequence between the disulfide and the organic radical $\mathrm{X}^{*}$ :

$$
\begin{aligned}
\mathrm{RSRR}+\mathrm{X}^{\bullet} & \rightarrow[\mathrm{RSSR}]^{+}+\mathrm{X}^{-} \\
\mathrm{X}^{-}+\mathrm{H}^{+} & \rightarrow \mathrm{XH} \\
{[\mathrm{RSSR}]^{+} } & \rightarrow[\mathrm{RS}]^{+}+\mathrm{RS}^{\bullet}
\end{aligned}
$$

In this reaction scheme the protecting mechanism is primarily an electron donation to the organic radical, the intermediate anion $\mathrm{X}^{-}$being neutralized by the $\mathrm{H}^{+}$ ions to yield $\mathrm{XH}$. This means that if $\mathrm{X}^{*}$ is a hydrogen abstraction radical, the disulfide under these conditions effects its repair as in the case of sulfhydryls. The radical $\mathrm{RS}^{\bullet}$ is, however, a secondary product resulting from the decay of the disulfenium cation [RSSR] $]^{+}$. The resulting low $\mathrm{RS}^{\bullet}$ concentration might explain why we failed to detect the triplet signal in the three-way flow experiments with disulfides. If, on the other hand, the disulfides are attacked directly with the very reactive species

${ }^{2} \mathrm{H}$. Dertinger and Cl. Nicolau, to be published in Biochim. Biophys. Acta. 
$\mathrm{OH}^{*}$, the $\mathrm{RS}$ radical reaches detectable concentrations (Fig. 1). The reasons why we could not obtain an EPR signal from the paramagnetic disulfenium cation are not understood. To our knowledge the spectrum of this species has not been observed so far in EPR experiments. Presumably the instability of [RSSR $]^{+}$yielding $[\mathrm{RS}]^{+}$and $\mathrm{RS}^{*}$ upon decay prevents build up of steady state concentrations high enough to be detected with EPR. The repair reaction proposed for disulfides are in agreement with the mechanism suggested by Owen et al. (24) to describe the initiation of the radiolytic decay of cystine solutions.

A short remark is necessary concerning the $\mathrm{pH}$ dependence of these reactions. At $\mathrm{pH}>3.5$, EDTA has to be added to the solutions to prevent precipitation of hydrolized Ti. At higher $\mathrm{pH}$ values, EDTA reacts with $\mathrm{OH}^{*}$ giving a characteristic EPR spectrum. In the presence of the sulfur compounds the EDTA radical is repaired, but no statement can be made concerning the fate of organic target molecules themselves because EDTA has to be present in excess. Due to this disadvantage, investigations of the kind reported here are confined to low $\mathrm{pH}$ values; that means, to substances that can be dissolved into acid aqueous solutions.

In spite of these restrictions the results reported are believed to be relevant for the problems of radioprotection. Compared with other techniques, the flow method has the unique advantage that the loci of target radical formation and their reaction with the sulfur compounds are spatially and temporally separated. This is, in fact, necessary to confirm that the most significant property of the sulfur compounds is really repair capability rather than ordinary scavenging ability.

\section{ACKNOWLEDGMENTS}

We are indebted to Prof. A Mïller for many stimulating discussions and Mrs. G. Kammerer for patient and skillful preparation of the manuscript.

ReCeIved: September 2, 1969.

\section{REFERENCES}

1. Z. M. BACQ, Chemical Prolection Against Ionizing Radiations. Thomas, Springfield, Illinois, 1965.

2. H. Dertinger and H. Jung, Molekulare Strahlenbiologie, Springer Verlag, Berlin, 1969.

3. M. G. Ormerod and P. Alexander, On the mechanism of radiation protection by cysteamine: An investigation by means of Electron Spin Resonance. Radiation Res. 18, 495509 (1963).

4. P. Mulvy and I. Pullman, ESR studies of spin-transfer in irradiated nucleic acid-cysteamine systems. Radiation Res. 34, 265-286 (1968).

5. R. BraAms, A mechanism for direct action of ionizing radiations. Nature 200, 752-754 (1963).

6. P. Alexander and A. Charlesby, Physico-chemical methods of protection against ionizing radiations. In: Radiobiology Symposium (Z. M. Bacq and P. Alexander, eds.), pp. 49-60, Academic Press, New York, 1955.

7. P. Howard-Flanders, Effect of oxygen on the radiosensitivity of bacteriophage in the presence of sulphydryl compounds. Nature 186, 485-487 (1961). 
8. T. HENRIKSEN, Radiation induced free radicals in sulfur compounds. ESR studies in the polyerystalline state. J. Chem. Phys. 37, 2189-2195 (1962).

9. Y. KURITA and W. Gordy, Electron spin resonance in a gamma-irradiated single crystal of L-cystine dihydrochloride. J. Chem. Phys. 34, 282-288 (1961).

10. G. Hotz and A. Múller, Der Einfluß von Cystein- und Cysteamin-Konzentration auf die Inaktivierung röntgenbestrahlter T-Phagen. Z. Naturforsch. 17B, 34-37 (1962).

11. G. E. Adams, G. S. McNaughton, and B. D. Mrchael, The pulse radiolysis of sulphur compounds, Part I. Cysteamine and Cystamine. In: The Chemistry of Ionization and Excilation (G. R. A. Johnson and G. Scholes, eds.), pp. 281-293, Taylor \& Francis, London, 1967.

12. G. E. Adams, G. S. McNaughton, and B. D. Michael, Pulse radiolysis of sulphur eompounds. Free radical "repair" by hydrogen transfer from sulphydryl compounds. Trans. Farad. Soc. 64, 902-910 (1968).

13. W. T. Dixon and R. O. C. Norman, Electron spin resonance studies of oxidation. Part I. Alcohols. J. Chem. Soc. (B) 1963, 3119 .

14. R. O. C. Norman and P. West, Electron spin resonance studies. Part XIX. Oxidation of organic radicals and the occurrence of chain processes during the reactions of some organic compounds with the hydroxyl-radical derived from hydrogen peroxide and metal ions. J. Chem. Soc. (B), 1969, 389-399.

15. W. A. Anmstrong and W. G. Humphreys, Amino acid radicals produced ehemically in aqueous solutions. ESR spectra and relation to radiolysis products. Can. J. Chem. 45, 2589-2597 (1967)

16. T. Henriksen, Energy transfer and radioprotection in biological systems. Scand. J. Clin. Lab. Invest. 22, 7-19 (1968)

17. W. FreYlaND and A. MÜLler, Radical formation in cysteamine free base and cystamine.2 $\mathrm{HCl}$ by reaction with atomic hydrogen and by gamma-irradiation. Int. J. Radial. Biol. 14, 482-485 (1969).

18. J. R. Morton, Electron spin resonance spectra of oriented radicals. Chem. Rev. 64, 453-471 (1964).

19. K. AKasaka, S. I. Ohnishi, T. Surta, and I. Nitta, ESR study of a single erystal of L-cystine dihydrochloride irradiated at low temperature. J. Chem. Phys, 40, 31103116 (1964).

20. K. Akasaka, Paramagnetic resonance in L-cysteine hydrochloride irradiated at $77^{\circ} \mathrm{K}$. J. Chem. Phys. 43, 1182-1184 (1963).

21. Y. S. Chiang, J. Cradnock, D. Mickrewich, and J. Turkevich, Study with fast-mixing techniques of the titanium (III) and hydrogen peroxide reaction. J. Phys. Chem. 70, 3509-3515 (1966).

22. G. E. Adams and B. D. Micha EL, Pulse radiolysis in radiobiology. In: Energetics and Mechanisms in Radiation Biology (G. O. Phillips, ed.) pp. 333-352, Academic Press, New York, 1968.

23. Cl. Nicolau, M. McMillan, and R. O. C. Norman, An ESR study of short lived free radicals derived from pyrimidines in aqueous solutions. Biochim. Biophys. Acla 174, 413-422 (1969).

24. T. G. Owen, M. Rodrigues, B. G. Johnson, and J. A. G. Roach, The radiation chemistry of biological disulfides. The low-dose $\mathrm{X}$-radiolysis of cystine. J. Amer. Chem. Soc. 90, 196-200 (1968). 